\title{
The Development of Supervisory Functions as Experienced by Attending Physicians and Medical Trainees: A Qualitative Directed Content Analysis
}

\author{
Soleiman Ahmady 1,2 , (D), Masoumeh Seidi, ${ }^{3, *}$ (i) \\ 'Head of Department of Medical Education, Virtual School of Medical Education and Management, Shahid Beheshti University of Medical Sciences, Tehran, Iran. \\ ${ }^{2}$ Research Affiliated Faculty at Department of Lime, Karolinska Institutet, Sweden. \\ ${ }^{3}$ Ph.D. Candidate of Medical Education, Virtual School of Medical Education and Management, Shahid Beheshti University of Medical Sciences, Tehran, Iran. \\ *Correspondence to: Masoumeh Seidi (E-mail: seidimasoomeh@gmail.com) \\ (Submitted: 15 April 2021 - Revised version received: 03 May 2021 - Accepted: 19 June 2021 - Published online: 26 August 2021)
}

\begin{abstract}
Objective This study aimed to identify the core components of supervisory functions experienced by attending physicians and medical trainees.

Methods This qualitative study was conducted based on the directed content analysis. Intentional sampling with maximum variation was used to select the required participants among medical trainees and attending physicians in teaching hospitals at Shahid Beheshti and Hamadan University of Medical Sciences, Iran. A semi-structured interview was used as the most important method of data collection in this study. Data saturation was reached after interviewing 20 participants.

Results In this study, 11 categories were identified through performing the interviews. Management supervision includes Academic Discipline and Monitor and follows the implementation of the curriculum. The themes of educational supervision were as follows: Empowering of non-faculty educators, Control over trainees' academic achievement, Supervision of trainees' performance, and Activities' educators of evaluation Supportive supervision included improving trainees' resilience, Provide functional support and Diversity and condition of providing support services. As well, the fourth theme from the participants' initial codes was observed to be professionalism, including Professional accountability and Respect for patient rights.

Conclusion This study highlighted the important aspects for which clinical supervision functions need to be improved, to maximize their benefit to medical students. Supervisors are responsible to ensure these three functions occur across the course. Care must be taken to ensure that one function does not become the focus.

Keywords Supervision, medical trainees, attending physicians, management, support, education
\end{abstract}

\section{Introduction}

Clinical Supervision is the provision of both advice and feedback on subjects correlated to personal, professional, and educational developments in the field of trainee experience. ${ }^{1}$ Some previous studies in this regard have shown that trainees are concerned about their uncertain future careers, unrealistic increases in a medical capacity, ${ }^{2,3}$ lack of knowledge and skills, and attending physician's (AP) criticism of trainee's activities. ${ }^{4}$ Based on the available pieces of evidence, it has been demonstrated that high levels of stress and anxiety during medical education may reduce trainees' focus, impair trainees' decision-making skills, and student's ability to communicate with patients effectively. ${ }^{5}$

The trainees can use many mechanisms to deal with his/ her stress, but many negative coping strategies also exist. The concept of coping is a stable behavioral and cognitive factor that helps in adjusting the body to stressful conditions. By considering this definition, two main types of coping can be known as follows: problem-focused coping, which is directed towards converting the problem or stressor; and emotionfocused coping, which is proposed to reduce individual emotional distress.

The clinical learning environment was found to have complex and multidimensional characteristics. ${ }^{7}$ Clinical supervision in teaching hospitals requires further appraisal and improvement.

In this literature, there was an agreement on clinical supervision with three functions, including management or administration, education, and support. Accordingly, all these functions are reflected in professions such as nursing ${ }^{9}$ and social work, ${ }^{10}$ which are recommended to be used in medical professions. ${ }^{1}$ The models dividing the functions of clinical supervision into three functions ${ }^{11}$ can be named as follows: Educational/formative/developmental function with emphasizing on learning and teaching. Additionally, the supportive, restorative, and resource function is the emotional response of supervisees. Moreover, the management/normative/qualitative function refers to the responsibility of the clinical function of supervisees and clinical outcomes for confirming the ethical quality of services. ${ }^{11,12}$ Correspondingly, each one of these functions may be highlighted or remain in the background of clinical supervision and circumstances. So, in this regard, it is essential to achieve some goals such as ensuring patient safety/care, teaching trainees, upgrading the standards, identifying trainees' problems, supporting trainees, and supervising trainees' progression. ${ }^{1}$ It was indicated that the current clinical supervision does not meet the needs of the medical trainees and these functions must be simultaneously applied to the supervision of the trainees. In this context, this study aimed to identify the core components of clinical supervision functions experienced by attending physicians (PAs) and medical trainees.

\section{Methods}

This study is a part of a doctoral dissertation in medical education approved by the Shahid Beheshti University of Medical Sciences, Teheran, Iran. The dissertation was designed at two stages. Accordingly, the first stage involved critically reviewing 
the support and supervision of medical students. What was shown by this article is included as a part of the 2 nd stage of the study (interviews with expert authorities). Moreover, we used a qualitative method with a directed content analysis method. The directed content analysis method aims to validate or expand a theoretical framework or theory conceptually. The existing theory or research can help in emphasizing the research question and also help researchers in beginning by identifying key concepts or variables as the initial coding categories. ${ }^{1}$

\section{Participants and Study Setting}

This study was performed at the Shahid Beheshti and Hamadan University of Medical Sciences in Iran. Medical trainees and APs were selected using purposive sampling, which continued until reaching data saturation. The participants were 11 medical trainees and nine attending physicians.

\section{Data Collection}

The needed data were collected through performing individual semi-structured in-depth interviews (in a quiet and comfortable atmosphere) from December 2019 to August 2020. A guide to open-ended interview questions was used following the predetermination of the themes. In the first step, the interviews were started with general open-ended questions (Table 1).

According to the willingness and preparedness of the participants, the interviews were recorded using a digital recording device. Each interview lasted for approximately 40 minutes (between 30 and 80 minutes). After transcribing and analyzing each interview, in case of any ambiguity and for probing into the participants' experiences, the interview was repeated to clarify different aspects of the subject, if needed.

\section{Data Analysis}

According to the directed content analysis process, at the commencement of each interview, the audio file was carefully transcribed and this text was then read several times to analyze the data. Thereafter, the texts were returned to the participants for their comments and correction. Subsequently, some important statements were made to identify the initial codes or semantic units in the text of the interview. In the next step, similar units were placed either in one of the following themes: managerial, educational, supportive supervision, and professionalism.

\section{Trustworthiness}

The prolonged engagement methods were employed to ensure the collection and analysis processes of actual trainee and AP experiences. The extracted text of some of the interviews, codes, subcategories, and categories was given to three faculty members (qualitative researchers) to evaluate the agreement reached on the meanings among several researchers. Maximum variation sampling (including age, gender, clinical phase, and specialty type) was used to adjust or transfer the results into other domains.

\begin{tabular}{|c|c|}
\hline \multirow{3}{*}{$\begin{array}{l}\text { Managerial } \\
\text { supervision }\end{array}$} & Could you explain your experience of holding a training class session at the bedside? \\
\hline & $\begin{array}{l}\text { What is your experience of compliance with administrative, educational, and ethical rules and regulations in } \\
\text { clinical education? }\end{array}$ \\
\hline & And ... \\
\hline \multirow{5}{*}{$\begin{array}{l}\text { Educational } \\
\text { supervision }\end{array}$} & What is your experience of a good teaching method in a clinical training course? \\
\hline & What are your experiences of teachers monitoring students' activities in the classroom and clinical environment? \\
\hline & In your experience, how do you monitor classroom and clinical activities? \\
\hline & $\begin{array}{l}\text { Go back to the past and describe one of the teacher supervision sessions in clinical education that has been } \\
\text { beneficial to you. }\end{array}$ \\
\hline & $\begin{array}{l}\text { Could you talk about the experience of using an advisor or counselor during education and how it affected your } \\
\text { academic achievement? }\end{array}$ \\
\hline \multirow{9}{*}{$\begin{array}{l}\text { Supportive } \\
\text { monitoring }\end{array}$} & What concerns and stresses did you experience during clinical education? \\
\hline & Could you please share your experience of being supported by a teacher? \\
\hline & Could you please share other students' experiences of being supported by a teacher during clinical education? \\
\hline & Could you please share your experience of communicating with APs in clinical courses? \\
\hline & In your experience, which roles of APs helped you reduce your stress or anxiety in your clinical course? \\
\hline & What training and supportive advice did you need during your clinical training course? \\
\hline & $\begin{array}{l}\text { During your previous internships, did you have any experience of not being supported by the teacher? Please } \\
\text { provide your expected support in that situation. }\end{array}$ \\
\hline & What experience and support did you receive during your previous internships? \\
\hline & And. \\
\hline \multicolumn{2}{|c|}{ Are there any additional experiences you would like to share? } \\
\hline
\end{tabular}




\section{Ethical Considerations}

The data were collected after obtaining the approval of the research proposal from the Ethics Committee of the Shahid Beheshti University of Medical Sciences (IR.SBMU.SME. REC.1398.061 Date: 2019-07-06). At the beginning of the interviews, the interviewer introduced himself to the interviewees, explained the goals of the research, and finally obtained informed consent.

\section{Results}

This qualitative study was conducted on 11 medical trainees; as 7 medical interns and 4 medical externs (The educational phases in the IRAN, basic science courses, pre-clinical, clerkship, and internship periods), including 4 men and 7 women; on nine Iranian attending physicians ( 3 men and 6 women), and on a different specialist (1 Internist, 1 Neurologist, 2 Obstetricians, 2 Neonatologist, 2 Pediatrician, and 1 Anesthesiologist) with the mean age of $41.12 \pm 6.11$ years old.
The components were broken down into the following three categories: managerial, educational, and supportive supervision (Table 2).

The following section is a summary describing the categories found in the interviews:

\section{Management Supervision}

\section{Academic Discipline}

Some APs do not believe in being strict in the classroom.

The AP (Neurologist, Male) marked, “...Absence and presence of trainees is an important matter to APs. I do not care about it though, because I believe that the class should be scientifically beneficial so that the trainee feels the need for attending the classroom in order to learn and feel that they would lose something if they do not attend the classes..."

An experienced medical trainee used the term messy when he was explaining the irregularity in the clinical setting.

\begin{tabular}{|c|c|c|}
\hline Themes & Categories & Subcategories \\
\hline \multirow[t]{2}{*}{$\begin{array}{l}\text { Management } \\
\text { supervision }\end{array}$} & Academic discipline & $\begin{array}{l}\text { - Encouragement and punishment's students } \\
\text { - The observance of educational rules and regulations } \\
\text { - Expectations of the student culture } \\
\text { - Organizing overcrowded rounds } \\
\text { - Reduction in the clinical education hours } \\
\text { - Multiple visits from patients by trainees } \\
\text { - Familiarize with the clinical field } \\
\text { - Presence of trainees }\end{array}$ \\
\hline & $\begin{array}{l}\text { Monitor and follows the implementation } \\
\text { of the curriculum }\end{array}$ & $\begin{array}{l}\text { - The appropriate implementation of educational programs } \\
\text { - The teaching performance of AP } \\
\text { - Security monitoring for students } \\
\text { - Patients'safety }\end{array}$ \\
\hline \multirow[t]{5}{*}{$\begin{array}{l}\text { Educational } \\
\text { supervision }\end{array}$} & Empowering non-faculty educators & $\begin{array}{l}\text { - Select the appropriate teaching method } \\
\text { - Methods for improvement of learning } \\
\text { - Accepting feedback }\end{array}$ \\
\hline & Competency-based assessment & $\begin{array}{l}\text { - Performance-oriented } \\
\text { - Inadequate content coverage of tests } \\
\text { - Design of knowledge-based questions } \\
\text { - Holistic of student evaluation }\end{array}$ \\
\hline & $\begin{array}{l}\text { Control over students'academic } \\
\text { achievement }\end{array}$ & $\begin{array}{l}\text { - Identify strong and weak students in education } \\
\text { - Classify students suffering from mental illness } \\
\text { - To strengthen weak students } \\
\text { - Offer opportunities to outstanding students } \\
\text { - Research opportunity } \\
\text { - Offering participation in scientific conferences } \\
\text { - Mentoring weak students }\end{array}$ \\
\hline & Supervision of students' performance & $\begin{array}{l}\text { - Factors influencing the amount of supervision } \\
\text { - The educational phases (internship or externship or clerkship) } \\
\text { - Type of supervisory } \\
\text { - Directly observing performance } \\
\text { - Review of patient records and documentation }\end{array}$ \\
\hline & Activities' educators of evaluation & $\begin{array}{l}\text { - Teaching quality } \\
\text { - Reduce teacher education role relative to other roles } \\
\text { - System expectations of faculty members } \\
\text { - Class management } \\
\text { - Make students aware of topics (daily lesson plan) } \\
\text { - Attraction to clinical education }\end{array}$ \\
\hline
\end{tabular}


Table 2. An overview of the related categories and sub-categories-Continued

\begin{tabular}{|c|c|c|}
\hline Themes & Categories & Subcategories \\
\hline \multirow[t]{3}{*}{$\begin{array}{l}\text { Supportive } \\
\text { supervision }\end{array}$} & Improving students' resilience & $\begin{array}{l}\text { - To Consider students' concerns } \\
\text { - Challenge clinical environment } \\
\text { - Imbalance between personal life and education } \\
\text { - Unpleasant feelings (seeing patients in pain, dying, etc.) } \\
\text { - The provision of advice and guidance } \\
\text { - Improved interaction between PAs and trainees } \\
\text { - Respect for trainees rights } \\
\text { - Assignment of a clinical advisor } \\
\text { - Wellness and entertainment programs exist } \\
\text { - Student adaptability } \\
\text { - Student enthusiasm } \\
\text { - Applying coping mechanisms }\end{array}$ \\
\hline & Provide functional support & $\begin{array}{l}\text { - Students interact } \\
\text { - Proper teacher-student relationship } \\
\text { - Set up a peer group } \\
\text { - Formation of social networks of consultants and APs } \\
\text { - Student-patient communication } \\
\text { - Student-employee communication } \\
\text { - Availability of APs }\end{array}$ \\
\hline & $\begin{array}{l}\text { Diversity and condition of providing } \\
\text { support services }\end{array}$ & $\begin{array}{l}\text { - Type of support facilities } \\
\text { - Avoid academic burnout } \\
\text { - Diversity in service delivery } \\
\text { - Well-being service } \\
\text { - Ensure confidentiality in the provision of services } \\
\text { - Having consultants out of the organization }\end{array}$ \\
\hline Professionalism & Professional accountability & $\begin{array}{l}\text { - Responsibilities to trainees } \\
\text { - AP's responsibility } \\
\text { - Observance of patients' rights } \\
\text { - Professional ethics in clinical educators }\end{array}$ \\
\hline
\end{tabular}

The trainee (2) said, “...Theoretical classes are held during the externship course at the hospital, which diminishes the number of hours spent at the patient's bedside and irregularity in multiple visits from patients by APs, residents, and trainees make clinical education messy and less important."

Rewards must be considered for the conscientiousness of trainees. In this regard, one of the trainees (1) stated, “... activities beyond our job description must be taken into account. While most of those who make a mistake is punished, a small number of trainees are rewarded for their proper performance."

\section{Monitor and Follows the Implementation of the Curriculum}

There are a variety of educational programs for medical trainees in clinical departments that should be followed by the head of the department.

One of the trainees (7) stated, "...The experts of education visit the clinical settings each semester to monitor the performance of the departments and ask if clinical educators teach these matters to trainees. I did not want to answer because I know from experience that nothing happens after monitoring it, and the same situation continues."

One of the trainees' about patient safety (3) explained, "When I was given patient responsibility. In the wards, I was worried about whether the test was correct or not. Are the patient's visit and diagnosis sufficient to treat the patient or not?"

Trainees are upset by some of the residents' behaviors. A trainee (8) stated, "...It appears that we have been imposed on some residents. Some of our questions are not replied to correctly. Some residents are bad-tempered."

\section{Educational Supervision}

\section{Empowering of Non-faculty Educators}

Regarding how to handle a class in clinical education, one of the APs (Surgeon, male) mentioned:

"...A good teaching method in clinical education boosts learners' motivation for providing healthcare services and encourages them to continue their activities. Trainees are completely engaged in the education process. Repeating theoretical issues at the bedside is not enough and all of them have been presented in books..."

The trainees mentioned that training courses are required for non-faculty physicians, residents, and a few faculty members.

The trainee (5) said, "...Many residents do not have the ability to provide information in an arranged and organized way and do not assess the trainee based on their real performances."

Another trainee (4) said, "Sometimes non-faculty members have taught us, and these physicians are experts in their profession but don't have the teaching skills..."

The reason for some trainees' lack of motivation to learn clinical skills was knowledge-based tests. The attending physician (Pediatrician, Female) stated, “...Unfortunately, several end-ofcourse tests and even residency tests measure most of the trainees' knowledge and memorization rather than clinical skills..."

\section{Control over Trainees' Academic Achievement}

Regarding trainee progress characteristics, one of the APs (Obstetricians, Female) stated: 
“... Regular attendance in the class, following and answering the questions raised in the sessions, pre-study before the session, expressing interest in the lesson presented, asking multiple questions from the others, and practically applying theoretical lessons..."

Another AP (Neonatologist, Female) expressed:

"... In the faculties, we often focus on trainees who have an academic failure, and those who are active and have the ability to grow and flourish are rarely identified to be rewarded. Meanwhile, these trainees will have good achievements for the university if they are counseled and usually work on good research topics..."

\section{Supervision of Trainees' Performance}

According to the APs' experiences, each trainee needs special supervision in different situations. The attending physician (Obstetricians, Female) explained, "...The amount of supervision for the trainee depends on whether the trainee is in an externship or internship course? In the externship course, everything must be conducted under the supervision of one person. However, the internship course is based on the trainee's experience, clinical skills, and motivation."

One of the APs (Pediatrician, Female) shared experiences about stepwise teaching of medical interns along with supervision:

"...When I ask one of the trainees to visit a patient, I monitor them both from far and near and evaluate what they write in the patient's medical files. Also, I assess how they face patients and inconspicuously control their activities by talking to the patient and their companions..."

\section{Activities' Educators of Evaluation}

The attending physician had a positive attitude toward receiving feedback from trainees about their teaching method. AP (Anesthesiologist, Male) claimed:

"... We can receive feedback from trainees verbally or in written form (anonymously) to improve our teaching. While trainees formally complete the AP's evaluation form at the university, I think that the conditions for answering, for example, the requirement to complete the form before the exams or before seeing the scores, make it difficult to be objective..."

The appropriate behavior of APs is effective in trainees' interest in lessons, classes, and disciplines.

Trainees (6) asserted:

"...I think the most important feature of an AP is their interest in the field of medicine. In addition, they should be well-tempered and have friendly behavior toward students, patients, and personnel."

\section{Supportive Supervision}

\section{Improving Trainees' Resilience}

One of the APs (Anesthesiologist, male) commented, “...Many trainees may become depressed due to the lack of specific regular environment in the hospital, course type change from theory to practice, long hours of clinical education, and trainees' challenges with medical and non-medical staff, multiple on-call shifts, and preparation for the residency exam. "

Trainees expect APs to understand their stressful situations and anticipate their needs. In this regard, trainee (4) expressed:
"...We expect APs to be compassionate towards their trainees and act like they are their own children. They are also demanded to have rational curiosity and learn about trainees' needs and understand how they feel from their appearance." Another trainee (8) affirmed:

"...Sometimes long shifts along with long training hours make trainees exhausted. This is especially true in hospital wards with a high patient load and a low number of trainees. On the other hand, preparing to report the end of the shift to the next intern and preparing for a round with the AP in the morning shift is difficult and the AP should understand trainees in these situations."

One of the trainees (3) talked about APs' disrespectful behavior:

"...I had a night shift and did not sleep at all. The next day, we had a round with the AP, who scolded me in front of other trainees for not knowing the answer to his question. What would he feel if he had not slept for 32 hours? I wish that he would put himself in my shoes for a second."

\section{Provide Functional Support}

The trainees mentioned are being APs as the exhibitor of experiences. One trainee (5) said, "...Many APs have few interactions with the trainees. I was interested in talking more with my AP as someone who has taken the course and using their experiences."

APs' respect toward the trainees increases patients' trust in trainees. In this regard, trainee (10) mentioned, “... In general, if the AP respects us in front of the patient, the patient will trust us, and on the other hand, the trainee will be more motivated to perform practical procedures in the hospital."

AP (Internist, Male) said, "...APs have shortcomings in their initial communication with trainees and cannot or do not want to interact with the trainee. They actually look down on trainees."

The AP should consider the differences in trainees' educational learning. In this regard, one of the trainees stated (11):

"...Some of the trainees need more practice and being scolded by the AP does not solve anything. If the AP does not have the time to do so, they should ask their resident to spend more time with that trainee and work on their problem. Trainees are different in terms of learning ability."

APs' availability and accompanying trainees and spending time with them were indicative of their support.

In this regard, AP (Pediatrician, Female) stated:

"...The personal growth of the trainees occurred by spending time with the trainees, accompanying them and being available to answer their questions. I tried to be patient enough and I did not get angry soon..."

Trainees also talked about their experiences using a group other than APs (e.g., residents and classmates).

In this respect, trainee (9) expressed:

"...Residents teach us instead of APs because we are the same age and we can communicate well and trainees can talk about their educational problems more easily."

Another of the trainee (2) marked:

"...We can use the experiences of higher-semester trainees regarding how to pass the courses and evaluate and communicate with APs."

\section{Diversity and Condition of Providing Support Services}

One of the important issues for trainees is the continuation of education and choosing a profession, and providing 
appropriate job counseling creates motivation for clinical work. Regarding choosing the future field of study, trainee (10) expressed, "...I would like to learn a specialty that is not in the clinical environment, such as radiology. This is because I do not like to see the death and pain of people."

One of the APs (Internist, Male) stated, "...I participated in the trainee tour several times as an accompanying AP. The main concern of trainees was their future job. They would ask whether they would be employed after receiving their degree or not. Another problem of these individuals was lack of having an income during education..."

In some cases, the AP refers to the support services. AP (Pediatrician, Female) said, "...If necessary, I will introduce related departments in the university, such as counseling centers, to the trainee to take care of their personal problems, their problems with other trainees and their family members, and issues that lead to academic failure..."

Another AP (Neonatologist, Female) expressed, “... Female trainees with family problems and divorce were given more time to do their homework. In addition, trainees with financial problems are referred to charitable people or other colleagues are notified to be aware of trainees' problems and do not remove their courses and give them more time if they are incapable of attending the classes due to working outside the faculty..."

\section{Professionalism}

\section{Professional Accountability}

A trainee (11) mentioned:

"... If I am assigned an activity or procedure by the AP, another person should follow up my work to confirm it or make the necessary changes."

One of the APs (Neonatologist, Female) commented on professionalisms' training as follows: “...Professionalisms' training should be provided for trainees during the medical course. For example, one of the educational goals of each course should be training professional and ethical responsibilities"

Attending physicians' participation in the clinical activities of trainees is a source of strength in trainees.

In this respect, trainees (5) mentioned, "... Some of the APs and residents had really good information and cooperated with us. They also carried out clinical procedures appropriately and explained everything with patience. They sometimes allowed us to perform the procedure and we had a really good feeling to have them by our side."

\section{Respect for Patient Rights}

Patients' rights are among the core principles in defining the standards of clinical services.

Sometimes the patient's room or the wardroom becomes very crowded and noisy.

One trainee (7) explained, "...The room of patients in training hospitals lacks sufficient space in order to respect their privacy. It is not easy for some of the patients to talk easily about their problems, which prevents their communication with healthcare providers..."

Trainees have expressed the professionalism of APs. One of the trainees (1) explained, "...Some of the APs devote great attention to the patients and patient satisfaction is highly important to them...."

\section{Discussion}

Based on the experience of attending physicians and medical trainees, the development of clinical supervision functions in undergraduate medical education mostly falls into the four themes.

\section{Management Supervision}

Management function mainly focuses on standards, policies, and procedures that are implemented and adhered to Performance assessment and management when there is a problem. ${ }^{14}$

The existence of the orientation program allows trainees to be better adapted to the environment in a clinical setting.

Therefore, designing a system of encouragement and punishment is essential to increase the quality of education.

Tarman (2016), in their study on American educational programs, stated two conflicting sets of attitudes toward discipline, one point of view maintained that the teacher's primary disciplinary task was to keep order, silence, and decorum in the classroom. On the other hand, the opposing point of view stated that teachers must place primary importance on developing a sense of personal worth along with a sense of inner control for the children in the classroom. ${ }^{15}$

The turnover of trainees provides an unprecedented overview of health care systems. Trainees should be able to recognize quality slots at first and then provide major suggestions. Moreover, trainees should be encouraged to contact the department directors about their clinical, administrative, vocational, and educational affairs to share their concerns in this regard. ${ }^{16}$

Notably, clinical educators should always observe the trainees' professional behavior and ethical principles, in order to provide timely and constructive feedback to them. In addition, the evaluation of professional behavior should not be limited only to final tests. ${ }^{17}$

Patient safety is considered the foundation of good patient care. Supervisors must ensure that the trainee is properly trained to perform a specific procedure and to apply specific elements related to patient care. Trainees whose behavior causes mental and physical harm to patients should be paid serious attention. ${ }^{18}$

Trainees must respect and reserve patient's information confidential. This includes limiting the discussion about patient health issues to the appropriate settings for clinical or educational purposes and only for those family member caregivers who are identified by patient consent. ${ }^{19}$

\section{Educational Supervision}

Educational practices can be defined as the learning and development of the trainee's knowledge or skills, as well as the creation of opportunities for teaching and learning. ${ }^{12}$

Medical trainees noted that clinical educators have good expertise; however, they are unable to transfer their knowledge and skills appropriately. Consequently, it appears that the focus should be on the education of non-academic physicians and residents in the first place.

The use of clinical rounds, which are considered an integral part of clinical teaching to help medical students acquire essential skills of practicing medicine, is critically important. ${ }^{20}$ Beigzadeh's (2019) study stated that, due to the importance of 
clinical rounds in students' learning, medical attending should break down their teaching sessions in activities pre-, during, and post-rounds. In another study by Beigzadeh (2019), their participants stated suggestions to diminish some barriers such as having fewer students on the rounds, addressing time constraints through planning and flexibility, and the provision of medical education rewards. ${ }^{20}$

Keshavarzi (2018) in a study mentioned that students' academic achievement is one of the important indicators of assessing university education. Teaching cognitive strategies in university education was found to be effective in fostering learners' learning skills and consequently their academic performance..$^{21}$

Educational supervision is deemed to be effective when educators support the progression of their trainees' learning by providing their access to appropriate training opportunities, to gain the required proficiencies. ${ }^{22}$

Most of the participants pointed out that each trainee requires special supervision in different situations. APs must also define the phases of development of each trainee and modify the type of supervision by several factors, including trainee progression level; the complexity of care or procedure; possible side effects, competence, maturity, and responsibility of each trainee; and patient's satisfaction. ${ }^{23}$ The faculty member is ultimately responsible for the evaluation, treatment, management, and documentation of each patient's care. ${ }^{24,25}$

Elson S. Floyd College of medicine previously stated that to ensure that medical students are appropriately supervised using the curriculum, some standards have been established by the Clinical Supervision of Medical Student Policy, which is as follows: Direct supervision, Indirect supervision, and With direct supervision available. ${ }^{26}$

A medical school faculty member regularly receives scheduled and timely feedbacks from departmental, other programmatic or institutional leaders on his or her academic performance and then progresses toward promotion, and when applicable, tenure. ${ }^{27}$

\section{Supportive Supervision}

Supportive supervision provides the psychological and interpersonal contexts that allow the student to mobilize the emotional energy necessary for having an effective performance and space for openness and aerial distress. ${ }^{9,28}$

Stress has some negative effects on trainees' learning and clinical success and also on the correct functioning of the shadow. ${ }^{4}$

Gang (2019) in the research stated that the quality of life of medical students is greatly affected by the presence of both anxiety and depression. Therefore, it is recommended that medical schools should implement some measures to identify vulnerable students and then provide comprehensive interventions and anticipatory programs for them, in order to improve their wellbeing. ${ }^{29}$

Shahraki (2019) also reported that both depression and anxiety affect the quality of life and stated that health conditions, psychological well-being, physical and social functioning, and environmental and spiritual aspects should be included in the quality of life assessment. ${ }^{30}$

The participants also highlighted the importance of having educators available during times of need or crisis.
In situations where clinical educators may be out of place, a good supervising physician (including a resident) should exist and should be aware of that expectation. The availability of APs was indicated to be directly correlated to learning progress and the increased trainees' satisfaction. ${ }^{31}$

Direct supervision means that the supervising physician is physically present with both the student and the patient. Moreover, Indirect supervision means that the supervising physician is not physically present with the student and the patient, but he/she will be immediately available to provide direct supervision upon any request, thus requiring that the supervising physician remain physically present within the hospital or other sites related to patient's care..$^{32}$

Functional support is a qualitative aspect of social support communication, social support is provided by individuals or groups, which consists of words, actions, and/or tangible aid that are perceived by the recipient as being positive. The result will be the provision of guidance and/or that the recipient's perception of him/herself, the problems, and the provider of support, his/ her sense of control or belonging, would positively be altered..$^{33}$

Peer (e.g., Residents and classmates) interaction can help in improving the effectiveness of the trainee's studies on test preparation and stress management during their undergraduate studies.

Crisp (2020) mentioned that peer support programs provide a promising approach to deal with the high levels of stress and psychological distress experienced by university students. However, few studies have considered the impacts of implementing programs on the well-being and skill development of student facilitators. ${ }^{34}$

Kemp's (2019) consensus statement provided some specific recommendations for medical schools, in order to design curricula that promote peer support and progressive levels of challenge to students, employ some strategies to promote positive outcomes from stress to help others in need, design assessment tasks to foster wellbeing and learning, provide mental health promotions and suicide prevention initiatives, provide physical health promotion initiatives, ensure about safe and health-promoting cultures for learning in on-campus and clinical settings, and train staff on student wellbeing and how to deal with wellbeing concerns. ${ }^{35}$

Vogan (2014) supported activities that can be included in the curriculum such as separate personalized assessment feedbacks, using stress decreasing techniques, career guidance, and personal and professional improvement sessions. ${ }^{36}$

Moir (2016) stated that peer-run plans have not been formally evaluated in the medical student population, where psychological issues exist and where it has been proven that students approach their peers for help in preference to staff members or professional services. It was demonstrated that one-fourth of intervention students use face-to-face peer support and more than $50 \%$ prefer a peer social event and/or participating in the mindfulness program. Several improvements were found in the mental health status of the intervention group, so there is evidence that peer support and mindfulness can be effective in other contexts. ${ }^{37}$

\section{Professionalism}

The Nursing and Midwifery Council in the UK (2009) stated that professional accountability is integral to professional 
practice, and is fundamentally concerned with weighing up the interests of patients and clients in often complex situations, whilst using professional knowledge, judgment and skills, based on the evidence, to make a decision.

The trainees are very happy to see the active involvement of the PA in clinical education and to follow his/her role as a model. Role modeling is at the core of building APs that show the knowledge, attitudes, and behaviors in identifying a good professional. $^{38}$

A doctor should interact with his/her patient by inspection, palpation, percussion, auscultation, and olfaction, and above all, by paying much attention in the direct discussion with him or her. During all these moments, the patient feels that he/she can interact with his/her doctor and then trust him or her. ${ }^{39}$

Fatemi (2016) in the study's results reported that two principal themes of facilitator factors and deterrent factors were obtained that respectively contain classes of (fruition of equal facilities and types of equipment, professional teachers, targeted educational plan, coordination and relationship between theory and practice, and the relationship between education programs) and (undesirable clinical realities, lack of expert and specialist teachers in practice, interpersonal communication, and unsuitable evaluation process), each one of which was found to be as effective on developing clinical educational equity process. ${ }^{40}$

\section{Conclusions}

At the same time, the perception of clinical supervision is known as a monitoring tool. It is evident that the managerial/ administrative office is much broader, which mostly includes assuming responsibilities to trainees and ensuring that they have been adjusted to the conventions and norms of organizations. It seems that two supportive and educational roles have disappeared result of management roles. Thus, it is necessary for educators to use the three clinical supervision functions simultaneously, in order to make sure all three functions occur during the course. Care should also be taken to ensure that a function does not become the primary purpose.

We sought to help a graduate with no stress and concerns, like an effective and competent physician, a respectable citizen, and a professional person. It is recommended to make some efforts to enable PAs in the practice of clinical supervision functions as well as the development of tools for assessing students on the basis of the above-mentioned three functions.

\section{Acknowledgments}

We wish to express our heartfelt thanks to all the participants of the Shahid Beheshti and Hamadan University of Medical Sciences who contributed to this study.

\section{Funding}

This article is part of a Ph.D. dissertation in Medical Education. This project was funded by Shahid Beheshti University of Medical Sciences.

\section{Disclosure Statement}

No potential conflicts of interest were identified.

\section{References}

1. Kilminster S, Cottrell D, Grant J, Jolly B. AMEE Guide No. 27: Effective educational and clinical supervision. Medical teacher. 2007;29(1):2-19.

2. Amiresmaili M, Nekoei Moghadam M, Moosazadeh M, Pahlavan E. Challenges of general practice education in Iran: A qualitative study. Strides in Development of Medical Education. 2013;9(2):118-131.

3. Nasri K, Kahbazy M, Noroozy A, Nasri S. The medical education problems and possible Solutions in stagers and intern's view points of Arak University of Medical Sciences, 2006-07. Journal of Arak University of Medical Sciences. 2010;12(4):111-121.

4. Yazdankhafard M, Poladi, SH. et al. The stressors of clinical education from students' point of view in Bushehr University of Medical Sciences. Iranian Journal of Medical Education. 2008:8:341-350.

5. Shapiro SL, Shapiro DE, Schwartz GE. Stress Management in Medical Education A Review of the Literature. Academic Medicine. 2000;75(7): 748-759.

6. Kahrazee F, Tamini BK, Daryasari SK, Mahdavi A, Kooteh BR, Qadimi A. Coping with Stress, Depression and Fear of Negative Social Evaluation through Comparing Wives of Addicted and non-Addicted Men. Maedica. 2018;13(4):305

7. Koohpayehzadeh J, Ahmadi MH, Dehnad A. Validity and reliability of activities coaching context questionnaire. Medical journal of the Islamic Republic of Iran. 2014;28:41

8. Razmjou S, Baradaran HR, Kouhpayehzadeh J, Soltani-Arabshahi K. Comparison of quality of clinical supervision as perceived by attending physicians and residents in university teaching hospitals in Tehran. Medical journal of the Islamic Republic of Iran. 2015;29:248.

9. Tuck JA. A new approach to team clinical supervision on an acute admissions unit. Mental Health Practice. 2017;20(5)

10. Kadushin A, Harkness D. Supervision in social work. Columbia University Press; 2014.

11. Basa v. Models of supervision in therapy, brief defining features. European Journal of Counselling Theory, Research and Practice. 2017;1(4):1-5.

12. Hawkins P, Shohet R. Supervision in the helping professions. McGraw-Hill Education (UK); 2012
13. Hsieh HF, Shannon SE. Three approaches to qualitative content analysis. Qualitative health research. 2005;15(9):1277-1288.

14. Gillieatt S, Martin R, Marchant T, Fielding A, Duncanson K. Evaluation of an inter-professional training program for student clinical supervision in Australia. Hum Resour Health. 2014;12:60.

15. Tarman B. Discipline or classroom management. Journal of Learning and Teaching in Digital Age. 2016;1(2):37-44.

16. Minnesota. Student Supervision During Clinical Activities.The University of Minnesota Medical School (UMMS). https://med.umn.edu/sites/med.umn edu/files/student_supervision_during_clinical_activities.pdf. Published 2019. Accessed.

17. Tabei S, Afshar L. Ethical considerations in Medical education and patient rights in educational hospital. Med Ethics Q. 2010;4(13):89-105.

18. Farajpour A, Afshar. Review of Ethical Consideration in Clinical Training; Propose Behavioral Codes in Iranian Educational System. Journal of Ahwaz Jundishapur University of Medical Sciences. 2016;1.

19. Columbia. Supervision of Students in Required Clinical Learning Experiences. Policy Advisory Subcommittee (PAS) MD Undergraduate Education Committee (MDUEC) the University of British Columbia. 2017; Next Review 2022.

20. Beigzadeh A, Bahaadinbeigy K, Adibi P, Yamani N. Identifying the challenges to good clinical rounds: a focus-group study of medical teachers. Journal of Advances in Medical Education \& Professionalism. 2019;7(2):62.

21. Keshavarzi MH, Safari E, Shakarabi M, Kangrani Farahani AR, Taghavinia M, Zabihi Zazoly A. The Effect of Teaching Cognitive Strategies on the Academic Achievement of Medical Students. Development Strategies in Medical Education. 2019;6(2):1-9.

22. Patel P. An evaluation of the current patterns and practices of educational supervision in postgraduate medical education in the UK. Perspectives on medical education. 2016;5(4):205-214

23. Florida. Medical Student Roles and Supervision. Florida Atlantic University Charles E. Schmidt College of Medicine (FAU COM). http://med.fau.edu/ faculty/documents/adminpolicies/Medical\%20Student\%20Roles\%20 and\%20Supervision\%20Policy.pdf. Published 2018. Accessed. 
24. Boston. Clinical Supervision Policy. Boston University School of Medicine. https://www.bumc.bu.edu/busm/files/2018/11/Clinical-Supervision-Policy. pdf. Published 2018. Accessed

25. MCGILL. Supervision Policy for Trainees in the Clinical Team. The University of MC GILL Faculty of medicine https://mcgill.ca/ugme/files/ugme/ supervision_policy_for_trainees_in_clinical_team_v1.1.pdf. Published 2016. Accessed.

26. ESFCOM. Clinical Supervision of Medical Students. Vice Dean for Academic and Community Partnerships.Washington State University. Elson S. Floyd College of Medicine. https://medicine.wsu.edu/ documents/2017/08/clinical-supervision-of-medical-students.pdf/. Published 2017. Accessed.

27. COLUMBIA. Expectations of Clinical Supervisors and Preceptors of Students in Clinical Settings. The University of BRITISH COLUMBIA. Date of Next Review:April 2021. https://mednet.med.ubc.ca/AboutUs/ PoliciesAndGuidelines/Policies\%20Guidelines/Supervision\%20 of\%20Students\%20in\%20\%20Required\%20Clinical\%20Learning\%20 Experiences\%20(031).pdf. Published 2018. Accessed.

28. Kadushin A, Harkness D. Supervision in social work. Columbia University Press; 2002.

29. Gan GG, Yuen Ling H. Anxiety, depression and quality of life of medical students in Malaysia. Med J Malaysia. 2019;74(1):57-61

30. Shahraki Z, Afshari M, Ghajarzadeh M, Tanha FD. How Different are Men with Infertility-Related Problems from Fertile Men in Prevalence of Depression, Anxiety and Quality of Life? Maedica. 2019;14(1):26.

31. Caspi J, Reid WJ. Educational supervision in social work: a task-centered model for field instruction and staff development. Columbia University Press; 2002.
32. WUSM. MD: Clinical Supervision Policy for Medical Students on Clinical Rotations. Approved by the Academic Affairs Committee. Washington University School of Medicine(WUSM). https://bulletin.wustl.edu/medicine/policies/mdclinical-supervision/md-clinical-supervision.pdf. Published 2020. Accessed.

33. Laack K. The role of social support in the success and retention of undergraduate nursing students. 2013

34. Crisp DA, Rickwood D, Martin B, Byrom N. Implementing a peer support program for improving university student wellbeing: the experience of program facilitators. Australian Journal of Education. 2020;64(2):113-126.

35. Kemp S, Hu W, Bishop J, et al. Medical student wellbeing-a consensus statement from Australia and New Zealand. BMC medical education. 2019;19(1):1-8.

36. Vogan CL, McKimm J, Da Silva AL, Grant A. Twelve tips for providing effective student support in undergraduate medical education. Medical teacher. 2014;36(6):480-485.

37. Moir F, Henning M, Hassed C, Moyes SA, Elley CR. A peer-support and mindfulness program to improve the mental health of medical students. Teaching and learning in medicine. 2016;28(3):293-302.

38. Park J, Woodrow SI, Reznick RK, Beales J, MacRae HM. Observation, reflection, and reinforcement: surgery faculty members' and residents' perceptions of how they learned professionalism. Academic medicine. 2010:85(1):134-139.

39. Cinteza M. The Stethoscope at the Age of 200: Will "He" Survive? Maedica. 2016;11(1):3.

40. Fatemi S, Moosavi S, Nikro R, Mohemkar-kherandish S. Exploration of Medical Sciences Students and Educational Custodians View about Educational Equity in Clinical Environment. Research in Medical Education. 2016;8(4):1-10. 